\title{
Revisiting Mixed Feelings
}

\section{Robert Zaborowski ${ }^{1}$ (D)}

Received: 3 May 2019 / Accepted: 22 June 2019 / Published online: 29 June 2019

(C) The Author(s) 2019

\begin{abstract}
In this article I first analyze the meaning of mixed feelings and what this expression refers to. I argue that what the term mixed feelings is commonly taken to mean are not mixed feelings because there is no mixture, and also because the same object and the same time condition of what is supposed to be mixed is not satisfied. I then pass on to a case of genuine mixed feelings. Genuinely mixed feelings are feelings composed of simple or basic feelings as well as occurrences of compounds and sets of feelings. I then discuss three categories adjacent to mixed feelings: layered feelings, metaemotions, and moods. Layered feelings are not mixed but superposed one over another, metaemotions have a mixed phenomenology, and moods are an affective mixture par excellence. In conclusion, I suggest that wrong labelling coincides with a category mistake which hampers further progress in the philosophy of affectivity.
\end{abstract}

Keywords Mixed feelings $\cdot$ Layered feelings $\cdot$ Metaemotions $\cdot$ Moods $\cdot$ Blended feelings

\section{Introduction}

[...] suddenly there arose within me two emotions, fear and desire

- fear of the threatening dark cavern,

desire to see whether there might be any marvellous thing therein [...]

L. da Vinci $(2008,247)$

\begin{abstract}
A shorter version of this paper was presented at the 4th EPSSE Conference, Sept. 15-17, 2017 in Madrid. I presented various ideas related to this theme in earlier talks given in Cork in 2010, Aberdeen in 2011, and Brighton in 2011. I am grateful to audiences in these places as well as to Demian Whiting and Bartłomiej Aleksiejczyk for their stimulating questions and useful remarks. I thank Robert Lee who checked and improved my poor English.
\end{abstract}

Robert Zaborowski

thymos2001@yahoo.fr

1 University of Warmia and Mazury, ul. Obiza 1, 10-725 Olsztyn, Poland 
In what follows I want to discuss the concept of mixed feelings. ${ }^{1}$ However, since the expression mixed feelings has acquired a specific meaning, ${ }^{2}$ I shall first focus on this, especially since I think that this is an imprecise phrase. But I take the dispute to be more than a merely terminological one. For this reason after having shown why it is inexact, I shall pass on to mixed feelings proper and, finally, I shall refer to other cases which, to some extent and with some provisos, may also fall under the umbrella of mixed feelings. This means that the aim of my paper is lexical only at the beginning, insofar as I deal with an obscuring expression. My main task will be to clarify the nature of what is referred to as mixed feelings and then to clarify the very essence of genuine mixed feelings. If this is successful, I hope to contribute to the philosophy of affectivity, better known under the label of philosophy of emotions.

Since the issue of mixed feelings is often treated together with, or confused with, affective ambivalence and/or affective conflict or, more broadly, inner conflict, a caveat is needed. These are three different issues. This is why, although they are interrelated with one another, they are better treated first separately. ${ }^{3}$ So-called mixed feelings refer to a feeling subject, while ambivalence is about not knowing what to do, ${ }^{4}$ and inner conflict concerns deliberation about how to act when

\footnotetext{
1 This is an important topic insofar as controversies around it concern both experimental and conceptual aspects. A recent special section on mixed emotions in Emotion Review 9 (2), 2017 attests to this. For instance, to take only three examples, while Watson and Stanton $(2017,102)$ are prudent and take "examples of bittersweet situations [as] subject to alternative explanations and do not necessarily prove that happiness and sadness can be experienced simultaneously [...]", Heavey, Lefforge, Lapping-Carr \& Hulburt $(2017,106)$ conclude that "[...] sometimes people experience multiple feelings blended together into one feeling experience, and that sometimes people experience multiple distinct feelings. [...] different feelings are merged or blended into one feeling experience". However, for them what we call "blended feelings" are "single feelings with multiple facets" (Heavey, Lefforge, Lapping-Carr \& Hulburt $(2017,108)$. As for Russell $(2017,116)$ his conclusion is more nuanced: "[...] if we speak loosely, ambivalence, mixed emotions, and bittersweet times occur. The key remaining issue on "mixed emotions" is conceptual. The concepts of emotion, feeling, affect, and mood continue to be used as if they are adequate scientifically when in fact they are vaguely defined folk concepts. These terms oversimplify a person's affective life and result in conceptual confusion. [...] On my conceptualization, "mixed emotions" typically include a mix of PAQs [i.e. perception of affective quality], a change in core affect, and often an EME [i.e. Emotional Meta-Experience], all potentially different in valence. The position here advocated is thus not bivariate but multivariate and bipolar". My approach in this paper is mainly categorial.

2 I also met "divided emotion" (in Pugmire 2005, 170), "mixed feeling" (in Pugmire 2005, 172) as well as "an ambivalent emotion" (in Kristjánsson 2010, 494). I must say I don’t understand how this may be so. As I take it, mixed (or ambivalent) is an agent or his situation or emotions, not a single emotion. Compare "[a]mbivalent emotional states" (Pugmire 2005, 170), "disharmony between emotions" (Pugmire 2005, 171), and: "there is no kind of emotion that is constitutively ambivalent" (Pugmire 2005, 171).

3 Pace Greenspan (1980).

4 Although Kristjánsson $(2010,488)$ uses "mixed emotions" and "ambivalent emotions" synonymously, he notes (487) that "[i]n cases of emotional ambivalence, two conflicting emotions are supposed to be fighting for predominance $[\ldots] "$, which is not the case when emotions are simply mixing or in mixture. As for ambivalence versus conflict Kristjánsson $(2010,487)$ specifies: "the 'psychological problem' surrounding emotional ambivalence admits of a solution. That problem has, however, often been conflated with a 'moral problem' - of how one should react morally to such ambivalence-which remains active even after the psychological one has been untangled $[\ldots]$ ".
} 
the ambivalence is conscious. ${ }^{5}$ Accordingly, mixed feelings do not always lead to ambivalence, which, in turn, does not always lead to conflict, ${ }^{6}$ while affective conflict presupposes affective ambivalence, which, in turn, presupposes mixed feelings.

\section{Various senses of mixed feelings}

\subsection{A Common Meaning}

There is, first, a meaning which is common and technical. For instance, the Cambridge English Dictionary reads for mixed feelings:

If you have mixed feelings about something, you feel both pleased and not pleased about it at the same time. (Cambridge English Dictionary 2017)

Insofar as this is a common language, a highly idiomatic sense is possible. But the idiom is used in philosophy as well:

contrary emotions with the same (propositional) object (Greenspan 1980, 228).

The point is that from the moment this idiom is taken as a technical expression and the expression is not accurate, we are in a difficult position for analysing the phenomenon this expression is supposed to describe. My worry is that (i) there is nothing mixed in what the expression mixed feeling refers to, (ii) mixed feelings do not have the same (propositional) object, and (iii) they do not occur at the same time.

\subsubsection{Where's the Mixture?}

Let me start pointing out the absence of mixture. ${ }^{7}$ When we hear that Paul likes and dislikes Peter there would be a mixture proper only if Paul either liked Peter less than when disliking was not occurring or if he disliked him less when Paul's liking were not occurring or, still, if Peter were indifferent to Paul because his liking and disliking were alike in strength. The mixture would be then a composition with characteristics resulting from the two components' characteristics. It would then be

\footnotetext{
${ }^{5}$ I leave this issue-i.e. ambivalence and affective conflict-for another paper/s. Compare Ledwig (2009, 174): "[...] the expression "mixed feelings" actually does not suggest a conflict, it only suggests that there are several feelings present [...]" and also Ledwig $(2009,186)$ : "In the case of mixed feelings, there do not have to be opposite emotions present, whereas in the case of emotional conflict this has to be the case".

${ }^{6}$ Compare the nice formulation by Ferrari (2007, 167-168): "It is a particular kind of mental conflict that the argument of Book 4 trains its eye on: not the dilemma arising from a mere coincidence of desires that cannot be simultaneously gratified, as when an invitation we would like to accept and a performance we would like to see fall on the same evening, but rather the wish to gratify a desire and, simultaneously, resistance to that wish; not two inclinations that happen to be incompatible but an inclination toward some action and a pulling back from that same action". (my underlining).

7 Compare Ledwig $(2009,160)$ : "[...] the expression "mixed feelings" [...] says nothing about what the mixture looks like $[\ldots] "$. For mixed feelings she provides a parallel of mixture of colours.
} 
more or less closer to the characteristics of the prevailing component or would be neutral if both were equal in strength. But this is exactly the opposite of what is meant. What is at issue when we refer to so-called mixed feelings is that we want to stress that Paul likes but also dislikes, or dislikes but also likes, Peter. Accordingly, we keep them-liking and disliking - as separate as possible. Where then does the idea of mixture come from? I think this is simply because we make an averaging or generalize different, often opposite, elements of the picture into one. This is similar to looking at a painting from a long distance: you may see a unicolour spot while its actual structure is fine-grained. If so, to speak about mixed feelings is to side with a neglectful observer and to miss the essence of occurring feelings. The observer perceives a mixture where there is none. ${ }^{8}$

Let us now look at other elements of the definition, i.e. at the same time and the same (propositional) object, to which one could add-following Plato ${ }^{9}$ and Aristo$\mathrm{tle}^{10}$ - other elements such as for the same reason, in the same respect, etc. It is not difficult to see that all of them are reducible to the same object, since if Paul likes Peter because of one feature and he dislikes him because of another feature, it may be said that Paul likes Peter's first feature while he dislikes Peter's other feature. More precisely, it is manifest that Paul likes Peter qua $\mathrm{x}\left(=\mathrm{P}_{\mathrm{x}}\right)$, while he dislikes him qua $\mathrm{y}\left(=\mathrm{P}_{\mathrm{y}}\right)$. This is to say that liking and disliking relate to two differently described or constructed persons $\left(\mathrm{P}_{\mathrm{x}}, \mathrm{P}_{\mathrm{y}}\right)$, that is, to two different objects. ${ }^{11}$

I think that the same is valid for the at the same time condition, for if Paul likes Peter today and dislikes him another day, we are dealing with two different objects, that is Peter at time ${ }_{1}$ and Peter at time ${ }_{2}$, since it is possible that Peter at time ${ }_{1}\left(=\mathrm{P}_{\mathrm{t} 1}\right)$ and Peter at time $e_{2}\left(=\mathrm{P}_{\mathrm{t} 2}\right)$ are not the same person, or at least, are not identically the same person. However, for an interesting reason (see below) I will treat the at the same condition separately. Let me focus therefore, first, on the same (propositional) object condition.

\footnotetext{
${ }^{8}$ In Sect. 1.2 (see below), the case will be wholly opposite: no mixture is perceived where there is one. For an analogy between feelings and colours see e.g. Geach (1957, 109): "I chose to set emotion-words and colour-words side by side, because there really is a considerable logical similarity. Both colours and emotions can occur in different intensities, and can wax and wane in intensity; there can be an emotion that is a blend of anger and fear, as there is a colour that is a blend of red and blue [...]".

9 See Plato (1967), Euthydemus 293c8-d1: "[...] so here you are, actually the very man that you are, and again, not that man, in regard to the same matter and at the same time!" (transl. W. R. M. Lamb). See also Plato (1969), Republic 436b8-9 and 436e9-437a2 and Plato (1921), Sophist 230b7-8.

10 See Aristotle (1933): "'It is impossible for the same attribute at once to belong and not to belong to the same thing and in the same relation"; and we must add any further qualifications that may be necessary to meet logical objections. This is the most certain of all principles, since it possesses the required definition [...]" (transl. H. Tredennick, my underlining, Aristotle (1894), Metaphysics 1005b19-

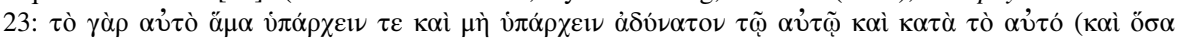

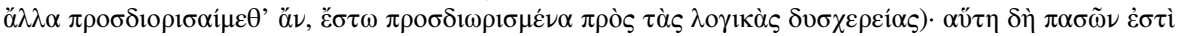

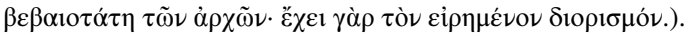

11 This is clear in the example discussed by Greenspan (1980, 228), for "I am happy that he won (feel good about his winning). I am unhappy that he won (feel bad about his winning)" amounts to "I am happy that he qua my friend won (feel good about his winning). I am unhappy that he qua my rival won (feel bad about his winning)", or again "I am happy that he won (feel good about his winning) because he deserves the honor. I am unhappy that he won (feel bad about his winning) because my own desire has been frustrated".
} 
Before that, however, I need to insert a remark. This is because quite often we hear about mixed feelings while opinions_-not feelings-are intended as when, for instance, someone asks: what do you think about yesterday's musical performance? If I think that it was good in some respects but bad in other respects, it is frequent that I say that I have mixed feelings towards it. ${ }^{12}$ But there are neither feelings nor mixture. I merely do not know how to express my judgment in a univocal way, especially if I am pressed to form it as simply and with no buts. I cannot do this and I maintain two distinct thoughts because the matter seems to me complex. From the two partial judgements a final one is formed. If so, it is a result of confronting the two-or more-elements. Retrospectively it may be called a mixture, but this is no more right than when we say that four is a mixture of minus one and five (and also several other, in fact countless, equations).

\subsubsection{The Same Object Condition}

What may be said about the same (propositional) object? Think, for instance, about any question asked in a general manner, for example: do you like travelling by bus? Or: do you like wine? Well, I answer, I like travelling when the bus goes smoothly and I like good wine, but I dislike travelling when the driver drives nervously and I dislike bad wine. Imagine, however, as is sometimes the case, that someone is still insisting because he wants to know your most general position without going into detail, and to hear either yes or no: do you like wine or not, please answer saying either yes or no? I am sorry, but insofar as I want to speak about the state of affairs as they are I am unable to answer anything in this way. Accordingly, since I have no answer to a question asked in this way I give no answer unless I am lazy ${ }^{13}$ or pressed by my interlocutor and say yes or rather yes having in mind a good wine or no or rather no having in mind a bad one, in which case I will probably be misunderstood by my questioner.

To use once again the analogy with colours: similarly, taken from a long distance and without going into detail a picture may look grey (in this case: yes or no), while it is, in fact, composed of black and white stripes (in this case: often yes but sometimes no or the other way round). I think we may reasonably suppose that the thinner the stripes, the better an eye should be equipped or it should be situated closer in order to grasp the actual structure of the picture and, similarly, the more nuanced

\footnotetext{
12 Ledwig $(2009,164)$ remarks that "we don't have the expression mixed beliefs [...] as we have it with regard to feelings". She finally subscribes-or so it seems-to the thesis that there are such things as "mixed feelings, ambivalent beliefs, and ambivalent perceptions". Her (Ledwig 2009, 166) example of mixed feelings is "switching from jealousy to emotions such as love and hate as opposites as one finds it in Othello's love for Desdemona". But switching by definition annihilates the at-the-same-time requirement (see below). She recognizes herself (Ledwig 2009, 168) that "[d]iachronic inconsistency is [...] a very weak form of inconsistency or even no inconsistency in the strict sense".

13 On laziness in description see Rorty (2010, 429-432), where what first looks like a case of ambivalence is shown not to be genuine ambivalence.
} 
are several feelings the more refined and sharp should be the approach to grasp them correctly and not as what appears as a mixture. ${ }^{14}$

I provide two, less prosaic, examples. The first comes from the Iliad III, 428-436, where Helen says to Paris (aka Alexander):

[...] Oh, how I wish you had died there beaten down by the stronger man, who was once my husband. [...] Go forth now and challenge warlike Menelaos once again to fight you in combat. But no: I advise you rather to let it be, and fight no longer with fair-haired Menelaos, strength against strength in single combat recklessly. You might very well go down before his spar.', Homer (1951), transl. R. Lattimore, my underlining)

Obviously, in Helen's case there are no explicit feelings, let alone words expressing explicit feelings. Instead we have propositions we must interpret. Yet it is not important whether they are read as expressions of Helen's anger versus care, or Helen's hatred versus love or anything else. The essential thing is that the two contrary feelings, whatever they are, produce her two opposite wishes. Many are perhaps ready to say that Helen's feelings towards Paris are mixed. This passage seemed so amazing to psychologically uneducated philologists that more than one wanted to athetize verses 432-436. I, however, would ask: how they may be mixed given that (i) the object of her anger or hatred is Paris qua coward (which is implied by what precedes, see Iliad III, 391-393, where we are told that Paris lies in his bed instead of being on the battlefield) and the object of Helen's care or love is Paris qua her present lover, and that (ii) the latter follows the former? These two aspects of Paris are distinct and so are the two feelings of Helen. Even if it is possible to regard the latter as provoked by the former, for instance by being so rude to him she notices her feelings of fondness, they are no less distinct than a cause and a result are distinct. And if the objects are not mixed, ${ }^{15}$ the feelings are not mixed either. ${ }^{16}$ This is why, to the question "[i]f a person encounters something that is both funny and sad, is she

\footnotetext{
14 Another reason for saying so may be that I do not know what I feel, let alone what to call my feelings, and then I use the phrase mixed feelings. I obfuscate the picture because of my epistemic limitations. Likewise, I think, in Rorty (2010, 429-431). The so-called ambivalence of the board concerning whom to appoint derives from their not knowing which candidate is, all things considered, better for the department. Aleksiejczyk (personal communication, May 2018) distinguished even more categories of undefined feelings or feelings hard or impossible to define: (i) feelings beyond the awareness (e.g. in a dream), though forgotten they still determine a person's mood, (ii) a feeling replaced by another one, (iii) a feeling undefinable because of the linguistic incapacity of a feeling subject. I think that Aleksiejczyk is right when he adds that the more minute the differences between components of a mixture are, or the weaker the feelings are, the harder it is to know whether what we perceive is as we perceive it or only seems to be so.

15 A similar remark in Massin $(2018,56)$ : "[...] only objectless feelings fuse [...]", since "for pleasures and displeasures with an object to be able to fuse, their objects should be able to fuse as well, which is unlikely".

16 It would be curious to imagine what a mixture of the two would be, say, a mixture of love and hatred: probably a sort of kind feeling penetrated by a sort of unkind one. Such cases are what the psychoanalysis tells us about. A confusion then must be disentangled so that the subject knows what her actual feelings are: kind feelings on the one hand and unkind feelings on the other, with either different objects (i.e. features located in the same person) or for a different reason, or still another different qualification.
} 
likely to be amused, saddened, or both?" (Elgin 2007, 40), I would answer: both. For if one aspect of the object is as funny as its other aspect is sad, we may expect the person to feel amused and saddened, and both of these to a degree corresponding to, respectively, the funniness and sadness of the object. ${ }^{17}$

Another example is borrowed from the Don Quixote:

[...] exceedingly pensive on the one hand, and very joyful on the other. His defeat caused his sadness, and his joy was occasioned by considering, that the disenchantment of Dulcinea was likely to effected [...] (Cervantes (2008), Don Quixote, ch. 71 (p. 924), transl. Ch. Jarvis, I underline).

Don Quixote's case is different because nothing is said about the sequence of Don Quixote's sadness and joy which lets us think that they may be simultaneous, and also because his sadness and joy have different causes (causaba), and, finally, because no object of either is specified. We may suppose that there are two, not one, propositional objects and as much as they are distinct, so too are the two feelings. Yet even if sadness (su tristeza) and joy (la alegría) occur simultaneously as general states, they are not mixed but distinct. If so, once again, we see that there is no mixture, especially such a mixture which would amount to one feeling being a mixture of all mixed elements and of which the characteristics would be a result of blending features of the mixed elements. There is no fusion as long as the components' features are not replaced by features of what results from blending. ${ }^{18}$ However, while Helen's feelings refer to two particular objects in a short time span, and probably with one following another, Don Quixote's feelings amount to a more general state of mind, with two feelings lasting for the same longer time span. ${ }^{19}$

\footnotetext{
${ }^{17}$ Ledwig $(2009,160)$ commenting on Feagin's examples of "amusement colored by contempt or contempt colored by amusement, says: [...] these are not two emotions but only one, for they blend into each other so much that we cannot say which is the more dominant". See also Ledwig $(2009,174)$ : "[...] the expression "mixed feelings" [...] only suggests that there are several feelings present which do not blend into each other".

${ }^{18}$ Massin $(2018,52-54)$ argues, convincingly in my view, against resultant feelings. In a word, if two components of a mixture produced a third-but separate from them-feeling, this would lead to an infinite regress. Consequently, the logic speaks for either two separate feelings and no mixture or a mixture of two in which the two are no longer discernible, at least precisely. Massin $(2018,55)$ also uses a comparison with "hot water and cold water blended in the same container". If the analogy is appropriate, it is illustrative. In point of fact, hot water and cold water in a container can be discriminated only approximately and this only as long as the two are not well mixed. From this moment on they are no longer discernible. Also illustrative is the case of facial expression. Consider, for instance, Odysseus's sardonic smile (Homer (1967), Odyssey 20, 301-302): is that $a$ mixture of several expressions still detectable and discernible corresponding to distinct feelings or one expression of several feelings mixed together? As for a more complex and mental level: an oft-quoted example of hope mixed with fear stands for one feeling being a mixture of hope and fear-that is, a feeling which is a complex one, neither pure hope nor pure fear, but a new one which we call hope-cum-fear probably because we have here no word for such a feeling — or for a feeling "alternating between hope and fear" (Roseman 2017, 138)? See also Heavey, Lefforge, Lapping-Carr \& Hulburt $(2017,107):$ "[...] little or no indication that there is any aggregated valence that results from their combined effect".

${ }^{19}$ I would tentatively draw the following distinction: (i) momentary feeling=starting and ending in this very moment, (ii) short-duration feeling $=$ feeling lasting more than in this very moment but of which the beginning and the end may be perceived or conceived, (iii) long-lasting feeling $=$ feeling of which the
} 


\subsubsection{At the Same Time Condition}

As I have said, I intend to treat the at the same time condition independently, even though it is reducible to the same object condition. This is because the same of the same object is much easier to delimit than the same of at the same time and, therefore, the latter is a less transparent qualification. It could even be argued that it is not transparent at all since we are hardly able to grasp the duration of a mental act in general and of affective acts in particular.

2.1.3.1 Simultaneity of the Class of Mental Acts 2.1.3.1.1 Exact simultaneity We may first think what at the same time exactly means. Is it to be taken precisely or approximately? Insofar as Helen's feelings occur one after another they are not simultaneous and, for this reason, they are not mixed since, when the second grows, the first is extinguished. But what about Don Quixote's joy and sadness or Paul's liking and disliking Peter given, of course, that the object of both feelings in both cases is still the same? As I take it, this is a condition together with a simultaneous occurrence of two opposite feelings necessary to consider anything like mixed feelings proper. This is because, if the same material object is taken in two different aspects or at a different moment, it is not, properly speaking, the same object but rather it, say X, splits into $\mathrm{X}_{1}$ and $\mathrm{X}_{2}$ where $_{1}$ and ${ }_{2}$ refer to two aspects or two moments. Briefly, the object, if it is to be the same, must be given in each case under exactly the same description. ${ }^{20}$

I start my analysis by looking at other families of the class of mental acts, first perception, and then thought. ${ }^{21} \mathrm{I}$ do this because something surprising will come out. As for perception, let us take a fine example provided by Jastrow's drawing of the head of a duck-rabbit. The dash might suggest that this is the head of both a duck and rabbit. In fact it may be both but it is either one or another at any single moment for any single eye looking at it.

It seems that the same is valid for thought. Think about so-called simultaneous chess games. I say so-called because actually when Kasparov participates in this kind of event, he plays with one player at one moment, however short or long it is.

\footnotetext{
Footnote 19 (continued)

beginning and the end cannot be perceived or determined. It goes without saying that the perception of this very moment is a subjective matter.

20 At this point, if not earlier (see above for Aristotle's "add[ing] any further qualifications that may be necessary to meet logical objections", transl. H. Tredennick), it has become evident that one should give a full list of qualifications in order not to add an ad hoc qualification each time all qualifications listed previously are satisfied. If not, it is always conceivable that another new one may be added to all those qualifications already listed. If, for instance, I say that I like and dislike Peter taken in the same respect and at the same time, it could be objected that maybe the reason for the two feelings is different, and then if I then say that I like and dislike Peter taken in the same respect, at the same time, and for the same reason, it will be objected that maybe the purpose of the two feelings is different and thus ad infinitum. Hence, another, still tinier qualification may be provided every time only for the sake of saving the principle of contradiction. But if so, the whole issue seems untreatable. On the Specter of Unfalsifiability in relation to mixed feelings see Larsen (2017, 120-121).

21 I suggest the following taxonomy: class=mental acts, families of that class=perception, thought, feeling, etc., genera (for family of feelings) $=$ fear, love, joy, etc., species (for genus of joy) = pleasure, cheerfulness, happiness, etc. Subspecies are possible.
} 
Certainly, to start 25 games with 25 players at the same place and going on playing with all of them during the same time span is much more complex and demanding than with one player at one event only. But there is no strict simultaneity. Each of the 25 games is, I suppose, discrete enough in Kasparov's mind. There is nothing mixed and he distinguishes perfectly what he has to do in every single game. ${ }^{22}$ A genuinely simultaneous game would consist rather of starting two games, each with one hand at the same time, playing with, say, two computers answering in exactly the same moment in such a way that Kasparov would have to think about how to play with them both at the same time and not first with one, next with the second. Who can imagine this ? $^{23}$ Accordingly, speaking about simultaneous games is an approximation to a similar degree as in the case of the above averaging or generalization of the opposite features of one object. Either each game is a separate one and then there is no mixture, or all games are mixed but then there is a total mess or, finally, the former happens but it is considered from a long distance and generalized in such a way as to call the event a simultaneous chess game (or games?), while it is not strictly simultaneous.

If the above is correct and there is no strict simultaneity in the case of perception and thinking (calculating), it is reasonable to assume that this is very much alike in the case of affectivity. But maybe this is wrong. Let us then look closer at it. In order to acknowledge affective simultaneity proper two feelings must happen at the same time over all the time they happen and not within the same time span but at different points of this time span, one after another and/or in a repetitive sequence. In a word, simultaneity, understood properly, concerns the whole duration of the time span in question and not just fragments of it.

Consider the following: you are driving a car. Your dog is close to you and you and your dog are about to have an extremely pleasant walk in a quiet forest just on the outskirts of your town. You have finished your paper as you wished, or even with

\footnotetext{
${ }^{22}$ See https://www.youtube.com/watch? $\mathrm{v}=1 \mathrm{sG} 7 \mathrm{sdF} 4 \mathrm{X} 8 \mathrm{k}$, where one may see, at 3'45', that Kasparov (2007) is busy-and how much — with only one player at once.

23 Compare LeDoux (1996, 269-270): "Remember this number: 783445. Now close your eyes and repeat it, and then count backward from 99 to 91 by 2 s and try repeating the number again. Chances are you can't. The reason for this is that thinking occurs in a mental workspace that has a limited capacity. When you started using the workspace to do the subtraction problem you bumped the stored number out". In the same vein Spitzer (2014, 13'08'') denies multitasking when it is understood as complex and-if I am correct-homogeneous activities, e.g. speaking with two people or reading two books simultaneously. He does not deny that one may read while walking or-the interviewer's example-cook while listening to music. Otherwise Man et al. $(2017,129)$ who argue that "the architecture of the brain allows for the simultaneous processing of both positive and negative information across multiple spatial scales". Yet this concerns the micro-level of analysis and they recognize that "[a]t the macro-level of analysis, large-scale systems of the brain are not dissociable into discrete positive and negative networks". I wonder if the distinction between the micro- and the macro-level does not amount to simple reactions to external stimuli, or bodily feeling at the most, and more complex responses respectively, say, psychic feelings, the latter being full-fledged emotional experiences. For instance, one may feel several bodily sensations at the same time, say hot in one leg, cold in another, pleasant in one hand and unpleasant in the other. See Schimmack $(2001,93)$. But it should be answered if there is a limit to that, and whether at some point sensation receptors are not blocked and feelings nullified with the result of producing only one or two general feelings.
} 
a better result, an important life problem has been just solved positively for you, the weather is perfect, etc. I suppose you will enjoy the walk or are already enjoying thinking about it. But as you are driving your dog is not calm at all. More especially, it is agitated each time you are in a difficult driving situation and, unfortunately, there is an entirely unexpected traffic jam because of an accident. Your dog's barking from time to time and/or rubbing you coincides with your challenging traffic situation and makes your trip even more complicated and, unsurprisingly, unpleasant.

The question is: do you feel simultaneously pleasantness because of your prospective walk and unpleasantness because of your current unease? Again, I think, it may be said that what is felt is mixed only if by mixed we mean that (i) what is felt is neither exclusively pleasant nor unpleasant, or that (ii) the pleasantness and unpleasantness are distinct. She who says that she has mixed feelings only says so while there is no mixture whatsoever, for if it were her pleasantness and unpleasantness would be no longer two distinct feelings. I would surmise that when pleasantness and unpleasantness are not too intense, they may not be simultaneous, or rather either one or another may occur in the foreground while the other is in the background, or they may alternate so quickly or extremely quickly as to produce an impression of simultaneity. ${ }^{24}$ In the case of not-intense feelings we may therefore speak about alternating in the sense of coming to the fore-retreating to the background-re-coming to the fore-re-retreating to the background-..., while if they are intense this is rather alternating in the sense of emerging — vanishing - reemerging - re-vanishing _ .... This is because intensity thwarts or reduces the other counterpart severely.

Take the example of an activity. One may play the same melody on two instruments. What about playing two different melodies? Or what about an outstanding violinist speaking with his colleague during a competition? This may be possible, but surely the quality of his playing would be lowered. Usually these things are to be avoided. This is not to deny that while playing an instrumentalist makes several operations at the same time. But they are components of that act of playing and-as such-are mixed or merged, or better, coordinated. This is not exactly the picture of seeing both the rabbit's and the duck's head, or of being both in joy and in sorrow, or both being angry and caring in all the cases in which these acts are separable and identifiable as distinct. As much as they are merged as constituents of the same act,

\footnotetext{
${ }^{24}$ Compare Kahneman $(1992,306)$ : "[...] experienced both as a gain and as a loss, at different times. Reversible figures [...] provide a useful analogy. There is no stable intermediate state with such figures; at any one instant, the percept is one or the other of the two solutions. [...]". There is a similar interpretation in Pugmire $(2005,173)$ who speaks about a serial model, i.e. wavering without having two feelings at the same time, which only may seem to be such if the wavering is fast enough. Although Heavey, Lefforge, Lapping-Carr \& Hulburt $(2017,108)$ call it a "plausible speculation", they do not provide any other evidence against it than absence of "reports of people experiencing rapid vacillation between positive and negative feelings" together with the reliability of their method "well suited to discovering such vacillation". More cautious is Larsen $(2017,119)$ who points to "threats to the specificity of all measures of core affect that have been used in the study of mixed emotions to date [...]". Larsen $(2017,119)$ remarks that "[t]he psychological moment may last for as little as $100 \mathrm{~ms}[\ldots]$. If core affect can change 10 times a second, we cannot expect people to press buttons fast enough to keep up with those changes". Larsen (2017, 120) concludes: "mixed smiles have been documented, but it is not clear whether they reflect mixed emotions".
} 
they are inseparable and even indistinguishable. Likewise, when I have a conversation with you while listening to what you say now I still remember what you-and I- have said before, not to speak about remembering the beginning of a sentence when finishing it. This is, again, a part of the same act: talking, producing a sentence, thinking what to ask next etc. ${ }^{25}$ But imagine playing chess in such a way as intending to win and to lose at the same time, or saying two different sentences, or rather, since we have but one mouth, writing two sentences with different, or with opposite senses, with your two hands.

Now, it may be that while seeing the duck I am aware that I can see (it as) a rabbit, or I feel ashamed when I ponder what to do. This looks as if two acts of distinct families could co-exist, e.g. perception and awareness. Also, it is possible to walk and shake hands or smell and watch. But how intensely may each of these be performed? Again, a parallel with thought may be helpful. For instance, I may be browsing the internet while answering the phone and giving my bank account password-however, neither should be too complex. If, however, my password is too complex, I am unable to browse the internet as much as before focusing on my bank account password. I must focus on it and focus means: devote my attention to it entirely or at least intensely. I have to concentrate on one of two actions, stopping or slowing the other. Similarly with feelings: either two relatively intense feelings do not occur simultaneously or if they occur simultaneously this is because they are relatively weak. ${ }^{26}$ Only in retrospect may I say: well, the drive with my dog was so-so, which means that on the on hand it was pleasant and on the other unpleasant. In fact it was not mixed, i.e. pleasant-unpleasant but rather pleasant-cum-unpleasant.

There is, finally, another issue inherent in what the same in at the same time means, which is to determine how long a time span is meant. Is it a year, a month, a day or an hour? For it may be that if two feelings happen at the same hour they happen at different minutes, and if they happen at the same minute they happen at different seconds and so on and so forth. Since a minute is composed of seconds, a second of milliseconds, a millisecond of microseconds etc., for this reason alone the qualification at-the-same-time (or simultaneously) can be inapplicable. This is why, in most cases, we deal with an approximation. For instance, if Paul liked Peter on the 1st, 3rd and 5th day and he disliked him on the 2nd and the 4th day, from one year perspective it may look as if he had so-called mixed feelings during these 5 days. But to say that Paul liked-disliked Peter for 5 days is again an inaccurate way of speaking. Or if John liked the film at the beginning and disliked it for the next

\footnotetext{
${ }^{25}$ Compare da Vinci $(2008,193)$ : "[...] for if the impression of the first note did not remain in the ear for some space of time the fifth which follows immediately after the first would seem alone; and a single note cannot create any harmony, and therefore any note sung alone would seem devoid of charm. Likewise the radiance of the sun or other luminous body remains in the eye for some time after it has been seen [...]". Also da Vinci $(2008,210)$ : "[...] nevertheless, we understand only one thing at a time. [...] So I say to you $[\ldots]$ not go on to the second until you have the first well fixed in memory and in practice".

26 There is a similar remark in Pugmire $(2005,175)$ : "contrary emotions that are actually about divergent aspects of the same thing are those not fully developed". They are not "consolidated" (181), or "fully consolidated" emotions (182).
} 
hour and again liked it at the end, it is sometimes said from a perspective of, say, 1 month, that he had mixed feelings about the film. Accordingly, many-but not all, not those who will not go into detail—will see that there are three different objects of John's liking and disliking the film. ${ }^{27}$

We may then conclude that either two (or more) feelings are mixed and inseparable or if they are separable and distinct they are not mixed. This is not a taste made up of, say, sweet and sour in such a way as to be sweet-sour. Rather what is labelled mixed feelings is similar to a collection of books-it may be called mixed but if it is called so this means that the observer lacks the discrimination necessary to distinguish the various topics of the books of this collection, which may, on this occasion, be disarranged on the shelves.

2.1.3.1.2 Not-An-Exact-Simultaneity This is, however, perhaps too rigid and we shouldn't look for at the same time but rather for during the same time span? We then would have in front of us not a literal simultaneity but rather a not-an-exactsimultaneity which comprehends two (or more) feelings occurring within a determined time span and within it they are not simultaneous but alternating. If alternation is fast, we may be left with an impression of their being simultaneous, but on a closer inspection we realise they are not. Accordingly, what stands then for simultaneity is alternation with a maximal tempo depending on the character of the opposed feelings. If, however, we accept this move and any mixture will obtain, this will be but an approximate, not-an-exact mixture.

If so, the issue now is to determine the time span involved and the maximal tempo of alternation. I start with the contention that both vary depending on the kind of feeling. What I mean is that the time span involved in an analysis of notexactly-simultaneous feelings comprehends a short(er) time span in the case of feelings typically short(er)-lasting and a long(er) time span in the case of feelings typically long(er)-lasting. ${ }^{28}$ For instance, for pleasure versus unpleasure (if you agree that both are short-duration phenomena), a shorter time span is needed to observe their not-an-exact-simultaneity than it is in the case of joy versus sorrow (if you agree that both are longer-lasting phenomena) and much shorter than in the case of happiness versus unhappiness (if you agree that both are long-lasting phenomena). ${ }^{29}$

\footnotetext{
27 Or-unless the film is perfect or a complete disaster-typically he may have both liked and disliked the film: the former because of its qualities (say special effects) and the latter because of its flaws (say the soundtrack). If I told someone that I liked-disliked the film period, this would be completely uninformative if not misleading since, in fact, the special effects were very good and the soundtrack was poor. Insofar as qualities and defects are distinct, nothing is mixed, although we may imagine a dull person who does not sufficiently distinguish the film's qualities and flaws and has, for this reason, quite a vague opinion-she might say mixed feelings - about the film. But all this is more relevant to the point discussed above, i.e. the same object condition. This proves that not only features of the object matter. The subject's affective skills, call them sensitivity, matter too, for Paul may be smarter in grasping distinctions which are non-existent, i.e. imperceptible, to Peter.

28 This is not to say that liking/disliking-but maybe not pleasure/unpleasure-may not last months or years. I think here of the minimal duration: love/hatred lasts not shorter than $\mathrm{x}$, liking/disliking lasts not shorter than $\mathrm{y}$, and $\mathrm{x}>\mathrm{y}$ (or even $\mathrm{x} \gg \mathrm{y}$ ).

29 Note that I do not oppose, for example, pleasure versus sorrow, happiness versus unpleasure etc. For the reason why, see Sect. 1.3 below. Note also that I do not take happiness in its common sense of feeling fine but in a sense of a deep and integral experience.
} 
If, for example, we agree that an average time span of pleasure is, say, $10 \mathrm{~min}$, the time span of not-an-exact-simultaneity covers in this case also $10 \mathrm{~min}$ and, consequently, our question in view of the pleasure's and unpleasure's occurring simultaneously is whether it is possible to experience both pleasure and unpleasure for the same 10 min. Any case of pleasure's and unpleasure's alternating within a time span longer than $10 \mathrm{~min}$, for example within the same day and alternating, say, every $2 \mathrm{~h}$, would be irrelevant for the issue of mixed feelings. If, on another hand, love is supposed to last typically, say, a year, simultaneous love and hatred, i.e. love and hatred occurring simultaneously, should be then understood as love and hatred occurring within the same year and not as love occurring one year and hatred another, previous or following year. ${ }^{30}$

If so, any alternation occurring within the time span in question testifies to two feelings occurring almost simultaneously but not any other which goes beyond the time span in question (say, love and hatred alternating every 5 years or pleasure and unpleasure alternating every $30 \mathrm{~min}$ ). Accordingly, the shorter the feeling the shorter the time span which is required in order to observe its almost-simultaneous occurrence with another, opposite feeling of a similar nature as to its duration. I think that the intuition that various feelings have different duration is confirmed by the fact that we accept more easily if Paul says that during, say, last year, his liking and disliking Peter were alternating several, say, 12 times, i.e. once a month on average, than if he says that during last year his loving and hating Peter were alternating

\footnotetext{
${ }^{30}$ See P. Greenspan (1980, 229): "[...] I would waver between them, feeling happy at some times, unhappy at others. [...] Thus, if I waver, over time, between happy and unhappy feelings about my rival's victory $[\ldots]$ we would reasonably conclude that I have "mixed feelings" throughout the overall time span involved, and not that I am continually changing my mind. But are my feelings really contrary emotions with precisely the same object? Someone might maintain that what I really feel bad about is not my rival's victory but my own loss". But if they are really mixed, how [might I] "sometimes manage to keep them rigidly distinct" (my underlining)? While I agree with Greenspan that no changing of mind occurs and that the object of happiness and unhappiness is different, I do not see how what is mixed may be kept distinct and/or what is kept distinct may be mixed. Moreover, I think that friendship is poorly constructed by Greenspan for, if we have in mind a genuine friendship, i.e. if it is a matter of two similar selves and if all things of friends are common (koina ta ton filon), then to present a friend as a rival is patently confusing. If we take friend as someone extremely close, say another I (allos ego), then it does not matter which part of my self wins, since in either case the victory is mine. Insofar as friendship is prior to rivalry it prevents rivalry's arising, or this is not a friendship, let alone a close one. But Greenspan persistently refers to the friend as my rival (Greenspan 1980, 228: "I am the rival of a close friend whose feelings I tend to share", 236: "[...] I am in a competition with a close friend", 237: "friendly rivalry"). If so, I do not see where there is friendship. Greenspan's crucial example is non sequitur and so is her argument. I think the same is valid for Kristjánsson (2010). His case 5 is badly constructed insofar as in the case of genuine friendship it is not "'After all, she is my best friend'" but rather 'First of all, she is my best friend' that makes sense. His case 7 ("'I am happy that she got the job but at the same time disappointed that she got it.'") is also badly built since the second element is a facade for, more accurately, "at the same time disappointed that I didn't get it". This is why it is not wrong to "insist that the two emotions in Case 7, the disappointment and the happiness, do not in fact have the same formal object, as the first focuses on the frustration of my desire and the second on the satisfaction of that of my friend" (Kristjánsson 2010, 492). In this respect I entirely concur with Pugmire $(2005,181)$ that "[i]t is hard to understand how I could rejoice at the prospect of a friend's expected good fortune and in the midst of my rejoicing also hope he comes to grief [...]. The difficulty here seems conceptual rather than psychological".
} 
12 times. In the same vein there is more sense in saying I like you, then I dislike you, then I like you again, all this happening during, say, winter holidays spent together and there is less sense in saying I love you, then I hate you, then I love you during the same two-week time span.

I cannot of course open the discussion of how long feelings of one or another kind typically last. This should be determined in another work. ${ }^{31}$ But if we agree that love (and hatred) is not an affair of a minute, hour, day or week, but rather of year, a case to be considered now is that of love and hatred occurring within the same year-with their object given under the same description both in love and in hatred-and not of love and hatred alternating within decennia which we may accept as perfectly plausible and having nothing to do with mixed feelings (just think about the one being extinct and the other having emerged, for instance someone whose love in the eighties evolved into hatred in the nineties). And the question is whether this is possible at all. According to Catullus in Carmen 85 it is, as may be inferred from the following:

Odi et amo. Quare id faciam, fortasse requiris.

Nescio, sed fieri sentio et excrucior.

(I hate and I love. Wherefore would I do this, perhaps you ask?

I do not know. But I feel that it happens and I am tortured., Catullus (19952013), transl. J. Neill)

Alas, we are not told how it is possible. The stress is put not on how it is possible but on what it causes. The poet is surprised by his own situation. But there is no evidence of his loving and hating. As long as no explanation of the fact described is provided it is unclear to what extent it is veridical. For instance it may be an avowal of someone who may very well be mistaken about her feelings or who in her overexcitement may name them inaccurately. It may be no more than licentia poetica

\footnotetext{
31 As well as to provide an answer to the question: what causes such differences to exist? Right now, and as a side note, I am inclined to suggest the following: if love digs deeper than liking and grasps a more solid value, this is because it hinges on the duration of that value (so-called untrue love is to be ruled out for obvious reasons). My intuition is that the more solid the value, the more durable is the feeling which hinges on it. If love grasps a value lasting longer than liking, then love qua love lasts longer than liking qua liking, all things being equal. Then, if liking or disliking and love or hatred refer to the same person, they grasp another feature or set of features in the same person, or if they grasp the same feature or set of features they grasp them, respectively, in a shallower and deeper way, where shallower stands for (more) partial and deeper for (more) complete. But maybe it would be more accurate to say that love/hatred are not only deeper but also wider in the sense that Paul may like a feature/value A in Peter and dislikes a feature/value B in Peter in the same time, while he may not love a feature/value A in Peter and hate a feature/value B in Peter at the same time. Rather he may love one set of features/values in Peter and hate another set of features/values in Peter in the same time. Accordingly, a person may possess two opposite features if they are relatively shallow, i.e. deserving liking and disliking, but not as deep as to deserve love and hatred. But this is tentative insofar as it leads quickly to Euthyphro's paradox (in Plato 1966): is a character of feature/value which determines the character of feeling or a character of feeling which allows such and such a feature/value to be grasped? Also, if a person may possess two opposite sets of features/values as deeply as deserving, respectively, love and hatred, it may be asked where the unity of that person lies.
} 
or histrionic wording. ${ }^{32}$ Therefore, the famous distich is but verbal, or in any case it does not help us make any progress. But even if we accept it, we may suppose that this is not exactly the same object which is loved and hated (loving $x$ in her while hating $y$ in her, or loving $x$ in her because of $a$ but hating $x$ in her because of $b$ ). In fact, the two verbs lack an object which makes the matter even more obscure. Yet because of long(er) lasting affective phenomena-such as loving or liking over years - the issue of dispositional affectivity comes to the fore.

2.1.3.2 Feeling Dispositionally I will treat this briefly because whether longer lasting emotions are possible only as dispositions is a contentious issue within the debate on affectivity. However, since I have pointed out that an exact simultaneity of any opposite feelings is impossible, I do not need to treat long-lasting feelings more extensively, since the longer duration of feelings does not add or modify anything in this respect. Even if long-lasting feelings were mere dispositions, this would not harm my argument against the simultaneity of opposed feelings because, in each single moment, only one of two opposed dispositions would come to the fore and be activated as an event, while the other would then lie in the background, not to mention that most probably they would both differ either in object or reason or another aspect.

Let us admit, however, that opposite feelings in the same subject towards the same object within a long time span are plausible, provided feelings are considered to be dispositions. First, it is not clear that if Paul likes and dislikes Peter for several years-and we don't speak now about Paul's liking Peter on even months and Paul's liking Peter on odd months ${ }^{33}$ - Peter, in his being liked and disliked by Paul, is exactly the same object. Obviously, this may be a way of speaking, especially if he who does not want to go into detail and by means of a shortcut says: I like and dislike him. But on closer consideration it will be plain that, say, he likes his voice while he dislikes his gait and, supposedly, the same occurs in Catullus if love and hatred may coexist at all: Catullus loves (who? what?) for one thing, one reason and hates her for another thing, another reason. So, to say that Paul likes and dislikes Peter is a generalization or approximation of what is really going on. There is no such thing as Paul likes-dislikes Peter as occurs in the case of the shade which is blue-green, that is a mixture of blue and green.

Those who treat long-lasting emotions like dispositions may however point to the fact that two opposite dispositions may be held, since in our life we have various dispositions at the same time: I like one kind of music, dislike another one, have several preferences and things not preferred, desires and fears and so on and so forth, not to speak about holding various opinions and beliefs. First, I would reuse my above argument that in such cases it is hardly possible to have preference and lack of

\footnotetext{
32 Among other options one may point to: (i) the implausible plasticity of the subject who both loves and hates, (ii) an idiosyncratic use of the words love and hate.

${ }^{33} \mathrm{Be}$ it in the form either of one coming to the fore and another retreating to the background on even months and the opposite on odd months or of one emerging and the other vanishing on even months and the opposite on odd months. But even if it is argued that either happens, in neither case does coexistence take place.
} 
preference for the same object understood in the same way, for the same reason, and because of the same aspect. What could it be? I do not deny that my preferences and lack of preferences may evolve and what I was looking for last year I now prefer to avoid without knowing what it will be next year.

I want, however, more particularly to point out the fact that affective states are not dispositions, at least no more than knowledge that a person possesses but is not aware of in this very moment or which is not at the forefront of her consciousness. Just as someone who sleeps or reads a book does not think of another book, so Paul, who likes Peter, does not sense his liking at every single moment. But this does not mean that he stops liking him.

Now, I find the distinction made by Aristotle (2000) useful. For him:

[...] three things happen in the soul: feelings, capacities, and states [...]. By feelings [ $\pi \alpha \dot{\theta \eta}]$, I mean appetite, anger, fear, confidence, envy, joy, love, hate, longing, emulation, pity, in general anything accompanied by pleasure

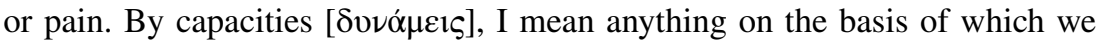
are described as being capable of these feelings, for example, on the basis of

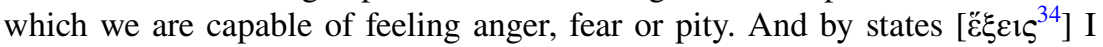
mean anything in respect of which we are well or badly disposed in relation to feelings, for example, in relation to anger, when we feel it too much or too little, we are badly disposed; but if we are between the two, then well disposed. And the same goes for the other cases. (EN 1105b19-28, transl. R. Crisp modified)

If we divide all classes of feelings into either episodic feelings or dispositional feelings, this would mean that the second group must be reallocated outside the class of affective phenomena proper because emotion and disposition are distinct categories. If we introduce something like a dispositional feeling this would demolish the whole Aristotelian schema. This may be the case and Aristotle may be wrong. But if he is right, as I think he is, they-call them dispositionalists-face the risk of regression since, in order to have a disposition to an emotion, one should have a disposition to have a disposition to have an emotion etc. ${ }^{35}$ Why? This is because, apart from

\footnotetext{
34 Translations of $\tilde{\varepsilon} \xi \varepsilon 1 \varsigma$ vary, e.g. Ross (in Aristotle 1908): "states of character", Rackham (in Aristotle 1947): "disposition", Rowe (in Aristotle 2002): "dispositions".

35 An anonymous reviewer, to whom I am grateful for his observation, remarked that the regression could be stopped if we distinguish two kinds of disposition, capacities and potentialities, in such a way that a potentiality is a disposition to have (acquire) a capacity: Paul is able (=a potentiality) to like Peter and after they have met, he is able (= a capacity) to like Peter in the sense that Paul often does not think about Peter and, consequently, does not like him. On this view, writing and liking are similar. As much as Paul is able to learn how to write he is able to like Peter, and as much as Paul may write once he has learnt how to write, he may feel a liking for Peter once he has acquired a capacity to like Peter. I am not sure if the dispositionalists makes a similar distinction between two kinds of disposition. But also I am not sure how to understand a capacity to like Peter and more especially in what it is different from being able potentially to like Peter. Unlike in the case of writing any skill (techne) is not required to be learnt in order to like. Of two people who are not writing at this very moment one may simply not be writing but is able to do so, whereas the other is not writing and cannot write. This is where the difference with feeling stops. It would be odd, I think, to say that Paul likes Peter but he does not like him at this very moment because, say, he is busy gardening. I agree that Paul's liking Peter is then in the background of
} 
feelings on the one hand and dispositions to feel so and so on the other, there would be a disposition to a disposition to feel so and so. But this makes no sense. Just compare: a human is able to learn to write and when she has learnt it she is able to write so and so and then she either writes so and so or not. However, when she is able to write because she has already learnt how to write she is also able not to write so and so and then may not write (i.e. refuse to write).

What about a feeling if it is a disposition? Paul is able to like Peter-we say this before, say, they meet for the first time. Now, after they have met for the first time it happens that Paul has liked (or disliked) Peter. And this is where the parallel with writing ends. Or are we to say that once Paul likes Peter he may still either like or not like Peter ${ }^{36}$ ? This would seem odd. If there is a long-lasting feeling or a feeling simply so long as to go beyond what is called an episode, it is not that, during its time span, in every single moment, it may or may not be felt (unlike with writing, for which in every single moment I may or may not write, or even when I am writing I may stop writing without losing my disposition for writing). Clearly, long-lasting feelings are not felt in the same way as are short-duration feelings, episodic feelings. They oscillate or even may be governed by a particular law of oscillation. ${ }^{37}$

A similar stance has been recently taken by D. Whiting $(2017,3)$. For him

all emotions are episodic and those states sometimes considered to be dispositional are not emotions proper. Although to talk about a disposition to undergo episodic fear when encountering spiders that amounts to saying a fear of spiders is not a state of fear at all [...].

This nicely complies with Aristotle's division, although Whiting does not refer to Aristotle. He remarks that what matters is not whether an emotion is an ongoing episode in every single moment but rather whether it shapes my behaviour and action. For instance, if fear of spiders were a mere disposition it wouldn't motivate me unless it became an episode. But this is not true. At this very moment I am busy with writing this paragraph rather than with my fear of spiders. Yet I have reached such a situation and position as to avoid any spider close to me. Suffice it to say that my position and/or situation is determined by my fear of spiders and if the presence of any fearful spider comes to my mind, my fear will modify my way of behaving and acting. ${ }^{38}$

To conclude this first part of the paper let me say that the label mixed feelings, though used frequently, is not accurate since it refers to a phenomenon which has

Footnote 35 (continued)

his awareness, but to assume that his liking Peter amounts to a capacity for liking Peter, a readiness to like him, is curious.

36 Of course he may stop liking him and start disliking him.

37 See Scheler $(1973,342)$ : "For psychic feelings are subject to their own laws of oscillation, as are the types of feelings of different strata in general [...]".

38 See Whiting $(2017,5)$ : "Commonly we suppose these mental states help explain action or at least our dispositions to action. For instance, we might say that my fear of spiders explains why I am disposed to avoid spiders. Thus, I would be in no way inclined to avoid spiders if it were not the case that spiders frighten me". 
little-or only vaguely_to do with a mixture of feelings. This is because either the two opposite feelings have different objects or occur for different reasons and as such can hardly be compared or, most often, they are not occurring simultaneously. In any case, they are distinct and if distinct they are not mixed. ${ }^{39}$ Only when considering herself from a long distance or in general does the subject have a vague impression of something mixed in her. On reflection she is more or less able to distinguish components of her state and recognizes that there are two separate feelings or groups of feelings, not only distinct but also separable and she may separate them from one another. If so, mixed feelings, if taken in the common and technical meaning, are non-existent. The expression is misleading and possible only because the expression is vague or made vague or obscured by generalization, approximation or averaging.

There is, however, another case in which feelings are genuinely mixed. I pass on now to this, even if, to my best knowledge, they have not yet received such a label. ${ }^{40}$ It is all the more surprising that this sense is not vague but literal and, I believe, accurate.

\subsection{Genuinely Mixed Feelings}

It is widely acknowledged that among feelings some feelings are basic or more basic than others. The latter are considered complex. Although there is no agreement as to the number of basic emotions nor which they are, the distinction is commonly understood in terms of basic feelings being simple and, like elements in chemistry, irreducible to others, ${ }^{41}$ versus complex feelings, that is feelings composed of the former. If so, they are occurrences of mixed feelings par excellence. But also the former, i.e. the simple, rarely happen, as it seems, in isolation. Rather, and quite often, they are experienced either in compounds or in sets. ${ }^{42}$ This corresponds to a general feature not only of many feelings but of many mental acts in general. Within the family of thinking a pure genus belief without any supposition or expectation without doubt is rare, and within the class of mental acts a pure thought without any feeling, or a feeling without thought is similarly infrequent. ${ }^{43}$ And these are, I

\footnotetext{
39 See also the motto to the paper, viz. L. da Vinci $(2008,247)$ who makes an accurate observation and does not call two feelings of his mixed.

${ }^{40}$ The closest I have found are primary dyads, secondary dyads, and tertiary dyads in Plutchik (1980, 161-163).

41 E.g. Descartes (2017), The Passions of the Soul, art. 69: "All the others are either composed from some of these six or they are species of them". (transl. J. Bennett) and Spinoza (2017), Ethics III, 57: "All the affects are related to desire, pleasure, or unpleasure, as the definitions I have given of them show". (transl. J. Bennett) to mention only two authors.

${ }^{42}$ The difference between a compound and a set is as between love-joy and love-and-joy, that is, in a compound elements are no longer distinguishable while in a set they are more or less distinguishable and identifiable.

43 That functions are not working in isolation is an opinion held by several neuroscientists, e.g. LeDoux (1996, 78): "Brain regions, in short, have functions because of the systems of which they are a part. And functions are properties of integrated systems rather than of isolated brain areas". If we take mental acts to be functions there is a strange parallel.
} 
think, the genuinely mixed feelings, for elements of a compound or a set (i) have the same object, (ii) occur simultaneously, and, finally, unlike the so-called mixed feelings, (iii) may be, and often are, formed of more than two. It is easy to observe that the elements of such mixtures do not stand-as is purported for so-called mixed feelings - in opposition. They are rather of similar character, that is of similar modi. And this is why-being similar-they are hardly separable and distinguishable when blended or mixed.

For instance, imagine the joy experienced by a child meeting his companion in kindergarten. He meets him after he was ill and did not come for several days. What may be told about his joy? Is this really pure joy and nothing more? Or is this only what it looks like, while in fact in his experience joy is a dominant constituent, prevailing to such an extent that it looks like pure joy? I am inclined to view it as what seems to us without determining nonetheless whether it is actually so. I would surmise that, together with the joy the little boy experiences, he feels confidence, courage, hope, desire and concern to mention but a few, and it is the intensity of joy which draws our attention to the most visible element of the whole picture. Probably the more intense is his joy, the more it looks like pure joy. If extremely strong intensity equals the highest degree of content of this element in the whole experience, then in an intense joy a presence of other feelings is modest or even negligible. And if they are negligible I do not know how I could argue for their co-presence. In order to do so I should have to prove a necessary link between joy and all the feelings I have mentioned. But this is where the crux lies. I do not claim that such a link is necessary. I think it would be even odd to claim so, since in another circumstances joy may be accompanied not only by other feelings but also the whole experience may be composed of its constituents in different proportions and in exceptional cases it may be pure. All I suggest is that often, or typically, a feeling co-occurs with other feelings or, to put it differently, rarely, if at all, does it occur in a pure and clearly isolated form. For instance, if we take surprise, longing or pride to be complex, their elements, let alone their formulas, are not as easily identified as, say, the elements and formula of carbonic acid. Therefore, even if one reason for our taking them as mixed may be purely epistemic ${ }^{44}$ and connected to our limited knowledge of affectivity, there is still another one of ontic order: compounds of feelings are not as stable in content as are chemical compounds.

If the above is correct, the difference with the so-called mixed feelings is all the more clear: while the so-called mixed feelings are separate and separable, the genuinely mixed feelings are not isolated and even hardly or only approximately isolable. If, however, I am wrong that feelings occurs mainly in sets or compounds, the claim the feelings are often mixed is still true because the number and occurrences of composed feelings are comparable if, not higher, to those of basic feelings.

\footnotetext{
44 See Ledwig (2009, 17): "Mixed feelings are only insofar a case of vagueness, when feelings oscillate between two different feelings over a time-span and where the boundary between the two different feelings is difficult to locate. That is, mixed feelings are so called, because the different feelings experienced do not blend into each other, and not because they are so mixed that they produce another feeling".
} 
At this juncture the reader may want to ask how I can assert that there is no simultaneity of feelings, or of any other mental acts, and, at the same time, claim that they occur rarely — at species, genus and class level-in isolation. I answer that this is possible only when elements are of such a mixed form as to create a compound or set, be it a mixture of mental families or a mixture of affective genera. ${ }^{45}$ This is the crucial point: when genuinely mixed, they occur together and since they are genuinely mixed, they are hardly dissociable.

In this section I have argued that there is a genuine case of fully-fledged mixed feelings, although the label of mixed feelings is not applied to it. This occurs when two feelings (i) have the same object, and (ii) occur at the same time. I have argued that this happens when - unlike in the case of so-called mixed feelings-feelings are similar. I have also tried to argue that—as components either of a compound or of a set-they may be more than just two.

If genuinely mixed feelings are made up typically of feelings of similar modi or at least of similar valence and so-called mixed feelings are most often applied to opposite feelings, these are but two kinds of special relation. It may be asked what about all other feelings, that is feelings which are neither opposite not similar (call them other or maybe neutral). This is exactly what I am going to do now: to take into consideration other feelings, although the following categories (Sects. 1.3, 1.4, 1.5) are not limited to other feelings. The following categories will include any kind of feelings: opposite, similar and other.

\subsection{Layered Feelings}

One sense which may look similar to mixed feelings, especially in view of the above considerations in Sects. 1.1 and 1.2, is a case of two (or more) feelings of different levels. In a sense, this is a case in between. I explain. When Paul is "“serene" and "calm" while experiencing a serious misfortune, for instance, a great loss of property [...]" or "can also drink a glass of wine while being unhappy and still enjoy the bouquet of the wine" (examples borrowed from Scheler 1973, 331), or when Paul drinks a glass of wine while being happy, there is no blending of calmness and misfortune or unhappiness and joy or happiness and joy ${ }^{46}$ into one (as in Sect. 1.1),

\footnotetext{
45 It is in this sense, it seems to me, that the expression mixed feelings (in the title of her paper) is understood by Frede (1996), for she speaks about one emotion containing other emotions (259, 263), about an emotion's "mixed nature" $(258,259)$, emotion as "intrinsically mixed phenomena" (259), "complex emotions" (263), "the mixed nature of certain emotions" (266), "amalgam of feelings" (268), and "emotions with inherently mixed nature" (276). More particularly, she remembers (267) that Aristotle "does not anywhere use the word "mixture," [...]". Finally, she explicitly rejects the common sense of the expression (269): "It is not because we are waffling or ambiguous in our attitudes, as the ordinary sense of "mixed feelings" would suggest". I suppose she also takes a similar position to my no thinking without feeling, no feeling without thought, when she says (258) that "crystal-clear cases hardly ever occur".

46 To avoid a confusion the following note may be useful. While pleasure is pleasant, not all that is pleasant is pleasure. Surely a state of happiness or bliss is pleasant without being pleasure or, rather, being more than just a pleasure. This is why, I think, Massin $(2018,51)$ is mistaken, unless he uses displeasure as a generic term for the whole genus, when he speaks about "a spiritual pleasure and a spiritual displeasure", especially if he has Scheler in mind as is the case. There is nothing similar in Scheler's For-
} 
but there is a simultaneity (as in Sect. 1.2). Yet not only opposite (as in Sect. 1.1) and similar (as in Sect. 1.2) feelings may be involved, but also any other kind of feeling (above called other). They do not mix, be they similar, opposite or other, for the simple reason that they are of different levels, which means they have a different ontic structure. ${ }^{47}$ According to Scheler:

The fact that there is no blending into one feeling, as is the case in feeling of such diverse levels of depth, points to the fact that feelings are not only of different qualities but also of different levels of depth. (Scheler 1973, 331).

But, it is easy to see that depth is a metaphor, although a recurrent one. ${ }^{48}$ Another description is required and I think it could be suggested that a feeling's belonging to a specific level depends on the way it grasps its object or-alternatively-on the kind of object it grasps, especially if this object is identified with value.

At first glance this may seem odd because it seems that enjoying a glass of wine while being unhappy is a different experience to enjoying a glass of wine while being happy. This is surely true and the two pictures taken each of them as a whole are different. Yet this is not to say that in the former case Paul enjoys the wine more than in the second. If his enjoying is actually about the wine this has nothing to do with his being happy or unhappy. Accordingly, regardless of his happiness or unhappiness he may well judge and enjoy the wine if he knows at all how to enjoy it. Now, if he is unhappy and the wine is disgusting his unhappiness is not greater because of that. He is still unhappy and, in addition, he has been served a bad wine. And similarly, if he is happy and has been served a bad wine, his happiness is not lessened by that. ${ }^{49}$ This lack of correlation and merging is evidenced by numerous examples known to moral philosophers, therapists, and many of us, for instance a wicked person who, although living in luxury, is unhappy or another who, although poor, is happy. In the same vein, a person may be scared by a snake but never experiences existential anxiety or, to show the opposite, may be indifferent to her physical security while anxious about the meaning of life or values that are in danger. Literature provides us with descriptions of this kind. They abound both in number and in variety.

To use again an analogy with colours let me refer to the well-known picture of emotions by Robert Plutchik representing eight modal groups of affectivity of which

\footnotetext{
Footnote 46 (continued)

malism $(1973,338-339)$. Scheler $(1973,338)$ rather speaks about "vital feelings [...] reduced to pleasure and displeasure [...] in contrast to psychic and spiritual feelings, e.g., sadness, woe, bliss, despair [...]".

47 In a similar, to some extent at least, sense Ledwig $(2009,176)$ : "Having contrary emotions on different levels, such as the unconscious and the conscious, is not a direct inconsistency, but only an indirect one and therefore does not seem so problematical, from a philosophical perspective".

48 Deep is sometimes interchangeable with high. See e.g. Robinson (2005), where she uses "deep" synonymously with "full", "hidden", "powerful", and "lasting". For Pugmire (2005, 190) the deeper, the closer to "the wholeness of one's mind".

49 Think about a mother of three sons who are about to be shot by a German officer, but as she puts herself at his feet, he agrees to spare one of them provided she chooses whom to spare (after Camus 1946, 3'45',-4'08',). Were her feelings mixed or was she rather totally happy at saving one and totally unhappy at losing the two others?
} 
each has three levels. The hierarchy, as I understand it, is represented by three circular zones. Now, it may be the case that my understanding of it flies in the face of Plutchik's purpose because, I suppose, he meant intensity rather than levels. If so, there should be no clearly distinct circles but only intensification (or weakening) of shades as, say, in a rainbow in which shades of one colour are not separated by lines but pass smoothly (and indistinguishably) one into another. In one point, however, Plutchik's diagram serves my purpose without proviso: it represents complex feelings as mixtures coming from simpler one, e.g. for Plutchik love is a mixture of serenity and acceptance.

The paradigm of layered feelings is present as early as in Homer, though the first philosophical analysis is offered by Plato who comments on the case of Leontius, who was - at the same time-presenting both desire and abhorrence. Each of them is linked to a different-hierarchically different- part of his self. $^{50}$

\subsection{Meta-Emotions}

I need also to add another case of feelings which, to some extent at least, fall under the umbrella of mixed feelings and/or simultaneous feelings: meta-emotions. ${ }^{51}$ For instance, I may feel pleasure because of my feeling unpleasure. There may be such a kind of unpleasure that I look for it. Or I may like being sad, or again, I may be ashamed of having pleasure in certain circumstance. The question is whether the two feelings occur simultaneously or subsequently. In either case nothing is mixed: there is no pleasure-unpleasure or liking-sadness or shame-pleasure. They are rather, as in Sect. 1.1 and in Sect. 1.3, two distinct feelings with two different objects. These are two distinct episodes of which the second is built on the first. The evidence is, I think, that if they were mixed I would feel no more, respectively, pleasure, liking and shame, whereas I feel each of them as long as there is an object for each, respectively, unpleasure, sadness, pleasure. What may seem mixed and even be mixed is their phenomenology, ${ }^{52}$ especially when a first-order and a second-order feeling are homonymously the same. ${ }^{53}$ They may then interact and influence one another as to

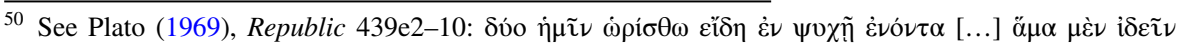

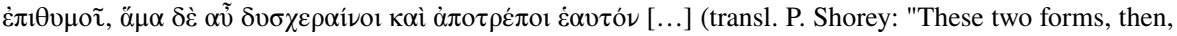
let us assume to have been marked off as actually existing in the soul. [...] at the same time felt a desire to see them and a repugnance and aversion").

51 I am grateful to Dina Mendonça for drawing my attention to this. Meta-emotions are sometimes referred to as layered emotions (e.g. Pugmire 2005, 174). This is obviously another sense of layered than in Sect. 1.3. I would call the latter ontic layeredness and the former epistemic layeredness.

52 See Mendonça $(2013,390)$ : "Though when emotion and metaemotion are simultaneous, their phenomenology intertwines, for example, when the feeling of being happy because one is happy reinforces the initial phenomenological state of happiness".

53 See Mendonça $(2013,391)$ : "[...] it seems easier to see the distinction when one is embarrassed about being angry or happy about missing someone, but it is less clear whether one could distinguish the two levels when one is angry about being angry, sad about feeling sad, or happy about happiness". Remark that here the use of level is entirely different from mine.
} 
their strength, for instance. ${ }^{54}$ If we now compare three people of which one is simply sad, another is sad and sad because of being sad, and a third one is sad and enjoys being sad, we may see to what extent they present different phenomenologies. Probably the intensity of sadness of the second person will seem the most strong and the intensity of the sadness of the last one will seem alleviated. Accordingly, we may say that the phenomenology is mixed or that the phenomenology of the first-order feeling and the phenomenology of the second-order feeling mix. But both feelings remain distinct because if an emotion's duration depends on its object and its object disappears, so does the emotion. And the same applies in this case: the existence of a metaemotion depends on its object. Since its object is another, first-order emotion, it exists no longer and no shorter than its object. This shows, I think, that the twofirst-order and second-order-feelings are distinct and if anyone calls them mixed this is because of a kind of epistemically insufficient capacity to distinguish their phenomenologies.

\subsection{Moods}

Still another case is that of moods. As is widely recognized,

[m]ood states are blended states. [...] A mood state is a blended state. At a given time, we always are in one, and only one, mood although we can have various emotions, say, feel contempt and anger towards one person and compassion towards another. (Stephan 2017, 1488-1489).

This is to say that a mood is a compound or a set of several emotions felt during what may be vaguely defined as the same time. Mood seems to be a more generalized case of Sect. 1.2 and, accordingly, is a mixture. Its constituents or components are identifiable only approximately. When I am in a mood-it seems that I am always in a kind of mood, or may I be moodless?-especially composed of dissimilar or opposed feelings I feel then my mood as being particularly mixed and difficult to identify and understand. If now mood is the general affective situation of a person, it is unsurprising that what was mistakenly taken for being a mixture in Sect. 1.1, here is fully and correctly comprehended as a mixture, insofar as the generalized expression of my affective state is complex. ${ }^{55}$

\footnotetext{
${ }^{54}$ See Mendonça $(2013,391)$ : "Feagin describes how a "blush of embarrassment may be intensified by embarrassment over the blush," such that no distinction of the two levels can be identified in the blushing of the person embarrassed".

${ }^{55}$ Compare Watson \& Stanton $(2017,103)$ who observe that "[m]ixed valence emotions-even those involving apparent opposites such as joy and sadness—can be identified in momentary mood ratings".
} 


\section{Conclusion}

In this paper I started with what is idiomatically and commonly called mixed feelings. I have argued that what the expression refers to are not mixed but unmixed feelings. As it stands, no mixture occurs because they are kept distinct, either because they have different objects or because they are not occurring exactly at the same time. This is manifest enough in the description given by the feeling subject (on the one hand I feel ... but on the other I feel ... or: I feel both ... and ...). ${ }^{56}$ Just as these are two distinct, unmixed facts or the same fact but given under two different and distinct descriptions, so there are no mixed feelings either. Were they mixed, they would be no longer distinct or even distinguishable. ${ }^{57}$ And yet they are distinct, or even easily distinct, because they are contrary. The impression of mixture is produced when a generalization or averaging from a long time span or the perspective of distance is at work. ${ }^{58}$ In other cases the expression mixed feelings refers to an opinion when a person refrains from judgment and prefers to be reticent about the value of what has just happened: she believes it neither entirely good nor entirely bad.

I then analyzed a case of genuinely mixed feelings. Although they are not usually labelled so, they represent the very essence of the mixture of feelings because the sameness of the object condition and the simultaneity condition are both satisfied.

Finally I touched upon layered feelings, metaemotions, and moods, which all lie close to the territory of mixed feelings proper. Layered feelings are not mixed but superposed one over another, metaemotions have a mixed phenomenology, and moods are an affective mixture par excellence.

If this is right, then to apply the label of mixed feelings as it is used to be is not only a linguistic error but-first and foremost-it is a category mistake. If, however, it is to be accepted that the expression mixed feelings used in its common

\footnotetext{
56 At the beginning of the paper I distinguished three issues: mixed feelings, ambivalence and inner conflict. I may now say that as much as I reject the common meaning of mixed feelings, I accept the affective ambivalence (Rorty 2010) and inner conflict (Price 1995).

57 The principle is set as early as by Anaxagoras (1948): "[...] Before these things were separated off, all things were together, nor was any colour distinguishable, for the mixing [ $\dot{\eta} \sigma 0 ́ \mu \mu 1 \xi 1 \varsigma]$ of all Things prevented this, (namely) the mixing of moist and dry and hot and cold and bright and dark, and there was a great quantity of earth in the mixture, and seeds infinite in number, not at all like one another". (Anaxagoras fr. DK59B4, transl. K. Freeman).

58 This is most explicit in Greenspan $(1980,232)$ : "[..] my contrary emotions need not "blend" into a single intermediate emotion, even after enough time has passed for me to $\underline{\text { sum }}$ their corresponding judgments: add them together, as a second step in their reconciliation, to form a single "all things considered" judgment, either: His winning is on the whole good. or: His winning is on the whole bad". Also Greenspan (1988, 111): "I have "mixed feelings," and consciously so, though one feeling or the other may dominate consciousness at any given time. Or the two may yield a kind of "mingled" pleasure/pain; but they do not blend into some sort of intermediate feeling tone". I have tried to show that on the whole perspective is the point of view of an observer but has nothing to do with the ontic situation of feelings observed-in what concerns feelings there is no such thing as a single ""all things considered" judgment" (Greenspan 1980, 234) in the case she describes. To take another example, a glass is both halfempty and half-full which may generate two distinct feelings. They are as distinct as the two facts, or maybe the two descriptions of the same fact, in this case: the glass being half-empty and the glass being half-full.
} 
sense is correct, it may then be answered that it is correct no more than it is to say that the sun rises (or sets): it points to the phenomenon but vaguely and misrepresents its nature. If so, it is not the best option for a philosophical discourse and may impede further advancement in the philosophy of affectivity. Otherwise it is correct if applied to an affective event composed of or including various feelings, mostly of similar modus or valence, which do not appear in isolation but blended. But then, to avoid a confusion, the label blended feelings may be proposed.

Open Access This article is distributed under the terms of the Creative Commons Attribution 4.0 International License (http://creativecommons.org/licenses/by/4.0/), which permits unrestricted use, distribution, and reproduction in any medium, provided you give appropriate credit to the original author(s) and the source, provide a link to the Creative Commons license, and indicate if changes were made.

\section{References}

Anaxagoras (1948) [fragments]. In: Freeman K (ed) Ancilla to the pre-socratic philosophers. Basil Blackwell, Oxford

Aristotle (1894) Ethica Nicomachea, (ed.) J Bywater. Clarendon Press, Oxford

Aristotle (1908) Ethica Nicomachea, transl. W. D. Ross. Clarendon Press, Oxford

Aristotle (1933) Metaphysics, transl. H. Tredennick. Harvard University Press - William Heinemann Ltd., Cambridge, MA - London

Aristotle (1947) Nicomachean ethics, transl. H. Rackham. Harvard University Press \& William Heinemann Ltd., Cambridge MA \& London

Aristotle (2000) Nicomachean ethics, transl. R. Crisp. Cambridge University Press, Cambridge

Aristotle (2002) Nicomachean ethics, transl. Ch. Rowe. Oxford University Press, Oxford

Cambridge English Dictionary (2017) Cambridge University Press, Cambridge (on-line, retrieved, 30 Jan 2018)

Camus A (1946) La crise de l'homme, a talk given at Columbia University, 28 Mar 28 1946. https:// soundcloud.com/user-497483266/la-crise-de-lhomme-discours-dalbert-camus. Retrieved 8 Sept 2018

Catullus (1995-2013) Carmen 85, transl. J. Neill. http://rudy.negenborn.net/catullus/text2/e85.htm. Retrieved 5 Oct 52017

da Vinci L (2008) Notebooks, transl. J. P. Richter, (ed.) Th Wells. Oxford University Press, Oxford

de Cervantes M (2008) Don Quixote, transl. C. Jarvis. Oxford University Press, Oxford

Descartes R (2017) The passions of the soul, transl. J. Bennett. http://www.earlymoderntexts.com/assets/ pdfs/descartes1649.pdf. Retrieved 25 Aug 2017

Elgin CZ (2007) Emotion and understanding. In: Brun G, Dogouglu U, Kunzle D (eds) Epistemology and emotions. Ashgate, London, pp 33-50

Ferrari GRF (2007) The three-part soul. In: Ferrari GRF (ed) The Cambridge companion to Plato's republic. Cambridge University Press, Cambridge, pp 165-201

Frede D (1996) Mixed feelings in Aristotle's rhetoric. In: Rorty AO (ed) Aristotle's rhetoric. University of California Press, Berkeley, pp 258-285

Geach P (1957) Mental acts: their content and their objects. Routledge \& Kegan Paul, London

Greenspan P (1980) A case of mixed feelings: ambivalence and the logic of emotion. In: Rorty AO (ed) Explaining emotions. University of California Press, Berkeley, pp 223-250

Greenspan P (1988) Emotions and reasons: an Inquiry into Emotional Justification. Routledge, London

Heavey ChL, Lefforge NL, Lapping-Carr L, Hulburt RT (2017) Mixed emotions: toward a phenomenology of blended and multiple feelings. Emot Rev 9(2):105-110

Homer (1951) Iliad, transl. R. Lattimore. The University of Chicago Press, Chicago \& London

Homer (1967) Odyssey, transl. R. Lattimore. Harper \& Row, New York

Kahneman D (1992) Reference points, anchors, norms, and mixed feelings. Organ Behav Hum Decis Process 51:296-312 
Kasparov G (2007) Simultaneous chess game. https://www.youtube.com/watch?v=lsG7sdF4X8k. Retrieved 2 Sept 2017

Kristjánsson K (2010) The trouble with ambivalent emotions. Philosophy 85(4):485-510

Larsen JT (2017) Holes in the case for mixed emotions. Emot Rev 9(2):118-123

LeDoux J (1996) The emotional brain. Simon and Schuster, New York

Ledwig M (2009) Mixed feelings. Emotional phenomena, rationality and vagueness. Ontos Verlag, Phenomena

Man V, Nohlen HU, Melo H, Cunningham WA (2017) Hierarchical brain systems support multiple representations of valence and mixed affect. Emot Rev 9(2):124-132

Massin O (2018) Bitter joys and sweet sorrows. In: Tappolet Ch, Teroni F, Konzelmann Ziv A (eds) Shadows of the soul. Philosophical perspectives on negatives emotions. Routledge, New York \& London, pp 50-59

Mendonça D (2013) Emotions about emotions. Emot Rev 5(4):390-396

Plato (1921) The Sophist, transl. Harold N. Fowler. Harvard University Press \& William Heinemann Ltd., Cambridge MA \& London

Plato (1966) Euthyphro, transl. W. R. M. Lamb. Harvard University Press \& William Heinemann Ltd., Cambridge MA \& London

Plato (1967) Euthydemus, transl. W. R. M. Lamb. Harvard University Press \& William Heinemann Ltd., Cambridge MA \& London

Plato (1969) Republic, transl. P. Shorey. Harvard University Press \& William Heinemann Ltd., Cambridge MA \& London

Plutchik R (1980) Emotion: a psychoevolutionary synthesis. Harper and Row, New York

Price A (1995) Mental conflict. Routledge, London

Pugmire D (2005) Sound sentiments: integrity in the emotions. Oxford University Press, Oxford

Robinson J (2005) Deeper than reason. Emotion and its role in literature, music, and art. Clarendon Press, Oxford

Rorty AO (2010) A plea for ambivalence. In: Goldie P (ed) The Oxford handbook of philosophy of emotion. Oxford University Press, Oxford, pp 425-444

Roseman IJ (2017) Transformative events: appraisal bases of passion and mixed emotions. Emot Rev 9(2):133-139

Russell JA (2017) Mixed emotions viewed from the psychological constructionist perspective. Emot Rev 9(2):111-117

Scheler M (1973) Formalism in ethics and non-formal ethics of values. A new attempt toward the foundation of an ethical personalism, transl. M. S. Frings \& R. L. Funk. Northwestern University Press, Evanston

Schimmack U (2001) Pleasure, displeasure, and mixed feelings: Are semantic opposites mutually exclusive? Cognit Emot 15(1):81-97

Spinoza (2017) Ethics, transl. J. Bennett. http://www.earlymoderntexts.com/assets/pdfs/spinoza1665.pdf. Retrieved 25 Aug 2017

Spitzer M (2014) Talking Germany. https://www.youtube.com/watch?v=4Ueg55KUQa0. Retrieved 3 Sept 2018

Stephan A (2017) Moods in layers. Philosophia 45:1481-1495

Watson D, Stanton K (2017) Emotion blends and mixed emotions in the hierarchical structure of affect. Emot Rev 9(2):99-104

Whiting D (2017) The myth of dispositional emotions. In: A paper given at the 3rd EPSSE conference, Jun 2016 in Athens (quoted with author's permission)

Publisher's Note Springer Nature remains neutral with regard to jurisdictional claims in published maps and institutional affiliations. 